\title{
ALONGAMENTO in vitro DE GENÓTIPOS DE Eucalyptus dunnii MAIDEN
}

\author{
Marcio Carlos Navroski ${ }^{*}$, Lia Rejane Silveira Reiniger ${ }^{2}$, Mariane de Oliveira Pereira ${ }^{3}$, \\ Aline Ritter Curti², Aline Ferreira Paim²
}

*Autor para correspondência: navroskiflorestal@yahoo.com.br

RESUMO: Brotações com pequeno alongamento poderão apresentar reduzida formação de raízes se forem diretamente cultivadas em meios de enraizamento ou, ainda, resultar em mudas de baixa qualidade para aclimatização. No presente estudo, objetivou-se avaliar o alongamento in vitro de genótipos de Eucalyptus dunnii sob diferentes concentrações de Ácido Giberélico (GA G $_{3}$. Segmentos nodais foram cultivados em meio nutritivo MS reduzido à metade da concentração de sais $\left({ }^{1} / 2 \mathrm{MS}\right)$ suplementado com $0,5 \mathrm{mg} \mathrm{L}^{-1}$ de Ácido alfa-Naftaleno Acético (ANA), $0,1 \mathrm{mg} \mathrm{L}^{-1}$ de 6-Benzilaminopurina (BAP), e variando-se o GA, conforme tratamentos. Utilizou-se delineamento inteiramente casualizado, em arranjo bifatorial 6 x 4, resultante da combinação de seis genótipos e quatro concentrações de $\mathrm{GA}_{3}\left(0,0 ; 0,2 ; 0,4\right.$ e $\left.0,8 \mathrm{mg} \mathrm{L}^{-1}\right)$. Após 30 dias de cultivo in vitro, foram efetuadas as avaliações. Para a maioria dos genótipos, a ausência de $\mathrm{GA}_{3}$ resultou no maior número de brotações alongadas por explante e maior comprimento de gemas alongadas. Em geral, os genótipos que apresentaram maior número de brotações também tiveram brotações maiores. Com o emprego da maior concentração testada de $\mathrm{GA}_{3}$, observou-se mais de 50\% de calogênese em um dos genótipos e intensidade diferenciada nos demais. GA não apresenta efeito no alongamento in vitro de Eucalyptus dunnii e, inclusive, em sua presença os genótipos reduzem o número de brotações alongadas e o comprimento das brotações, aumentando a formação de calos. Os genótipos de Eucalyptus dunnii avaliados apresentam desempenho in vitro diferenciado em relação ao alongamento, o qual é passível de seleção.

Palavras-chave: Ácido giberélico, cultura de tecidos, micropropagação, silvicultura clonal, reguladores de crescimento.

\section{In vitro ELONGATION OF MINICUTINGS OF Eucalyptus dunnii Maiden GENOTYPES}

ABSTRACT: Shoots that have short lengths may present low percentage of survival if they are directly grown on rooting media, or give rise to low quality seedlings for the acclimatization phase. The objective of this study was to evaluate the in vitro elongation of Eucalyptus dunnii minicuttings under different concentrations of giberellic acid. Minicuttings were prepared and inoculated under aseptic conditions on MS nutritive medium with half of the salt concentration $\left({ }_{1}^{1}{ }_{2} M S\right)$. We used fixed concentrations of NAA ( $\left.0.5 \mathrm{mg} L^{-1}\right)$ and $B A P\left(0.1 \mathrm{mg} \mathrm{L}^{-1}\right)$ varying $G A_{3}$ according to the treatment. The experiment was conducted in a randomized design, using a $6 \times 4$ factorial scheme, where the levels of factor " $A$ " refer to different genotypes and the levels of factor B, the concentrations of GA $(0.0$; $0.2 ; 0.4$, and $\left.0.8 \mathrm{mg} \mathrm{L}^{-1}\right)$, each replicate was composed of a flask containing three explants. Thirty days after in vitro culture, evaluations were performed. For most genotypes, the absence of $G A_{3}$ produced the highest number of elongated shoots for explant and a longer length of elongated shoots. In general, genotypes with the highest number of shoots also had larger shoots. The non-addition of GA 3 to the nutritive medium did not promote calli formation, reaching over $50 \%$ in the use of higher concentration of GA tested (0.80 $\mathrm{mg}$ $\left.L^{-1}\right)$. The calli formation was different in different genotypes. Gibberellic acid (GA $A_{3}$ ) has no effect on in vitro elongation of Eucalyptus dunnii. In the presence of $\mathrm{GA}_{3}$ genotypes reduce the number of elongated shoots and shoot length, increasing the formation of calli. The genotypes of Eucalyptus dunnii evaluated present differently in relation to in vitro elongation, which is able to be selected.

Key words: Giberellic acid, tissue culture, micropropagation, clonal forestry, plant growth regulators.

\section{INTRODUÇÃO}

As características florestais apresentadas por Eucalyptus dunnii oferecem perspectivas promissoras para o cultivo dessa espécie no Rio Grande do Sul. Entre essas características, merecem destaque a tolerância a geadas intensas e severas, e, também, o baixo potencial invasivo de Eucalyptus dunnii, que produz poucas sementes, dificultando sua propagação aleatória (BILLARD; LALLANA, 2005).

Por outro lado, a reduzida produção de sementes dificulta, em muito, a produção de mudas pela via sexual.
Alternativamente, devem ser pesquisados métodos de propagação assexuada, entre os quais vêm se sobressaindo, nos últimos anos, a micropropagação (ALFENAS et al., 2004).

$\mathrm{Na}$ área florestal, a micropropagação, encontrase embutida nos programas de melhoramento, que, na maioria das vezes, objetivam a maximização ou a manutenção do valor genético do clone a ser propagado, permitindo, assim, acelerar os métodos convencionais de propagação vegetativa, entre outras finalidades (XAVIER et al., 2009).

\footnotetext{
${ }^{1}$ Universidade do Estado de Santa Catarina - Lages, Santa Catarina, Brasil ${ }^{2}$ Universidade Federal de Santa Maria - Santa Maria, Rio Grande do Sul, Brasil

${ }^{3}$ Universidade Federal do Paraná - Curitiba, Paraná, Brasil
}

Cerne, Lavras, v. 19, n. 4, p. 545-550, out./dez. 2013 
Na micropropagação, sobre a fase de alongamento in vitro de Eucalyptus dunnii, em particular, poucos estudos foram realizados. Entretanto, essa etapa tem sido necessária para o sucesso do cultivo in vitro na maioria das espécies de Eucalyptus (CORREIA et al., 1995). As brotações multiplicadas que apresentam pequeno comprimento poderão apresentar reduzida rizogênese, se forem diretamente cultivadas em meios de enraizamento, ou dar origem a mudas de baixa qualidade para a fase, posterior, de aclimatização (SILVA, 2004).

Um dos fatores que afeta o alongamento in vitro de brotações está relacionado ao efeito residual de 6-Benzilaminopurina (BAP), utilizado durante a fase de multiplicação de gemas em subculturas sucessivas (GRATTAPAGLIA et al., 1987).

Uma das formas de estimular o crescimento das brotações é por meio da adição de Ácido Giberélico $\left(\mathrm{GA}_{3}\right)$ ao meio nutritivo, o qual promove o aumento do comprimento das brotações, pelo estimulo da divisão e alongamento das células (MÉTRAUX, 1987). A adição de $\mathrm{GA}_{3}$ também reverte parcialmente o efeito depressivo das citocininas sobre a proliferação de raízes (HU; WANG, 1983).

Em brotações de Eucalyptus globulus Labill. cultivadas in vitro, em meio de cultura MS, foram obtidas brotações alongadas com a adição de $0,1 \mathrm{mg}$ $\mathrm{L}^{-1}$ de $\mathrm{GA}_{3}$ (CALDERON-BALTIERRA, 1994). Além disso, essa concentração de $\mathrm{GA}_{3}$ resultou em melhorias na produtividade, na altura dos brotos e na taxa de enraizamento.

Objetivou-se, com o presente estudo, avaliar o alongamento in vitro de brotações de Eucalyptus dunnii sob diferentes concentrações de $\mathrm{GA}_{3}$.

\section{MATERIAL E MÉTODOS}

\subsection{Coleta e preparo do material genético}

O material genético utilizado no presente estudo foi coletado em plantio comercial localizado no município de Alegrete - RS, com cerca de três anos de idade, originados pelo plantio de mudas produzidas por sementes.

Foram escolhidas 10 árvores com altura e diâmetro superior, bom desenvolvimento de copas, desprovidas de sintomas de deficiência nutricional ou hídrica e de ataques de pragas e doenças. As árvores selecionadas foram abatidas, deixando-se uma cepa com cerca de 45 $\mathrm{cm}$ de altura. Na sequência, após o início das brotações, foram realizados tratamentos sanitários preventivos com a aplicação intercalada, semanalmente, dos fungicidas Captan ${ }^{\circledR}$ (Dicarboximida), a 2,4 $\mathrm{g} \mathrm{L}^{-1}$, e Benomyl ${ }^{\circledR}$ (Benzimidazol), a $1,0 \mathrm{~g} \mathrm{~L}^{-1}$.

Decorridos 60 dias do abate das árvores, foram coletadas brotações (1-1,5 cm de comprimento) das árvores selecionadas. Foram coletados o $3^{\circ}$ e o $4^{\circ}$ par de folhas do ápice em direção à base, posição geralmente utilizada para formar microestacas de Eucalyptus (XAVIER et al., 2009).

As brotações foram coletadas nas primeiras horas da manhã, acondicionadas em frascos de vidro contendo água destilada e autoclavada acrescida de Ácido Ascórbico a $1 \%(\mathrm{p} / \mathrm{v})$ para minimizar o efeito da oxidação fenólica. Os frascos contendo essas brotações foram colocados em caixa de isopor contendo gelo e transportados até o Laboratório de Biotecnologia Vegetal localizado no Departamento de Fitotecnia da Universidade Federal de Santa Maria

A desinfestação foi efetuada em capela de fluxo laminar, e as brotações, após eliminação das partes oxidadas, foram inoculadas em frascos, contendo $30 \mathrm{ml}$ do meio nutritivo MS (MURASHIGE; SKOOG, 1962). Decorridos 30 dias do estabelecimento dos explantes, segmentos nodais de seis genótipos (de número 2, 3, 4, 6,7 e 10) que obtiveram estabelecimento superior a $30 \%$ foram transferidos para a fase de multiplicação. Durante essa fase, os explantes foram cultivados em meio nutritivo MS cuja concentração de sais foi reduzida à metade $(1 / 2$ MS), acrescido de $0,01 \mathrm{mg} \mathrm{L}^{-1}$ de Ácido alfa-Naftaleno Acético (ANA) e $0,25 \mathrm{mg} \mathrm{L}^{-1}$ de 6-Benzilaminopurina (BAP), permanecendo nessa condição por mais 30 dias.

\subsection{Alongamento in vitro das gemas}

Para a iniciação da fase de alongamento, as brotações multiplicadas in vitro foram preparadas e inoculadas, sob condições assépticas, em frascos com capacidade para $150 \mathrm{ml}$, contendo $30 \mathrm{ml}$ de meio nutritivo 1/2MS (MURASHIGE; SKOOG, 1962), acrescido de $6 \mathrm{~g} \mathrm{~L}^{-1}$ de ágar, $30 \mathrm{~g} \mathrm{~L}^{-1}$ de sacarose e $50 \mathrm{mg} \mathrm{L}^{-1}$ de mio-inositol.

$\mathrm{O}$ meio nutritivo foi preparado utilizando-se água deionizada e o pH foi ajustado para 5,8, antes da adição do ágar e da autoclavagem. Na sequência, os frascos foram vedados com papel alumínio e autoclavados a $121^{\circ} \mathrm{C}(1,5$

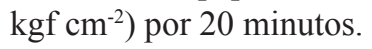

Os frascos contendo os explantes inoculados foram mantidos em sala de cultivo com temperatura de $25 \pm 2{ }^{\circ} \mathrm{C}$, fotoperíodo de 16 horas e intensidade luminosa de $20 \mu \mathrm{mol}$ $\mathrm{m}^{-2} \mathrm{~s}^{-1}$ fornecida por lâmpadas fluorescentes brancas frias tipo luz do dia durante todo o experimento.

Cerne, Lavras, v. 19, n. 4, p. 545-550, out./dez. 2013 
Utilizaram-se concentrações fixas de ANA $(0,5$ $\left.\mathrm{mg} \mathrm{L}^{-1}\right)$ e de BAP $\left(0,1 \mathrm{mg} \mathrm{L}^{-1}\right)$, variando-se o $\mathrm{GA}_{3}$, conforme tratamentos. $\mathrm{O}$ experimento foi realizado em delineamento inteiramente casualizado, utilizando-se um esquema bifatorial $6 \times 4$, em que os níveis do fator "A", referiram-se aos diferentes genótipos e os níveis do fator "B", às concentrações de $\mathrm{GA}_{3}$ avaliadas $(0,0 ; 0,2$; 0,4 ; e $0,8 \mathrm{mg} \mathrm{L}^{-1}$ ). Foram usadas cinco repetições, cada uma composta por um frasco contendo três explantes, totalizando 120 unidades experimentais e 360 segmentos nodais introduzidos in vitro.

Trinta dias após a inoculação dos explantes, foram avaliadas as seguintes variáveis: número de brotações alongadas (NB), comprimento das brotações alongadas (CMB, em mm) e porcentagem de formação de calos (formação de calo em qualquer parte do explante).

\subsection{Análises estatísticas}

Após avaliar a normalidade dos erros pelo teste de Kolmogorov-Smirnov e a homogeneidade de variâncias por meio do teste de Bartlett, os dados foram transformados pela função $\sqrt{x+0,5}$ e submetidos à análise de variância. Quando o valor de "F" foi significativo, médias de tratamentos qualitativos foram submetidos à comparação de médias por meio do teste de Scott-Knott ao nível de 5\% de probabilidade de erro. Médias de tratamentos quantitativos foram submetidas à análise de regressão polinomial. Os resultados apresentados são as médias originais obtidas. O programa estatístico SISVAR (FERREIRA, 2000) foi utilizado para a análise estatística dos dados.

A precisão dos experimentos foi medida pela acurácia seletiva (AS) calculada por $\sqrt{1-1 / \text { Fcal }}$, que corresponde à correlação linear entre os valores genotípicos e fenotípicos.

\section{RESULTADOS E DISCUSSÃO}

Houve interação $(p<0,01)$ entre os fatores testados para número de brotações alongadas por explante e comprimento médio de brotações (Tabela 1). Para a formação de calos, houve efeito significativo dos fatores principais genótipo e $\mathrm{GA}_{3}$. A acurácia seletiva (AS) foi elevada para as três variáveis avaliadas, conforme classificação de Resende e Duarte (2007), demonstrando alta confiança na avaliação e nos valores genotípicos preditos com fins de seleção. A estatística AS não depende apenas da magnitude do erro experimental e do número de repetições, mas também da proporção entre as variações de natureza genética e residual associadas ao caráter em avaliação.
Tabela 1 - Resultado da análise de variância para número de brotações alongadas por explante (NB), comprimento médio de brotações (CMB) e porcentagem de formação de calos em segmentos nodais de seis genótipos de Eucalyptus dunnii submetidos a diferentes concentrações de $\mathrm{GA}_{3}$, após 30 dias de cultivo in vitro em meio nutritivo $1 / 2$ MS. Santa Maria-RS/ UFSM, 2010.

Table 1-Results of analysis of variance for number of elongated shoots per explant (NB), mean length of shoots (CMB) and percentage of calli formation in nodal segments of six genotypes of Eucalyptus dunnii subjected to different concentrations of $G A_{3}$, after 30 days of in vitro culture on $1 / 2$ MS nutrient medium. Santa Maria-RS/UFSM, 2010.

\begin{tabular}{|c|c|c|c|c|}
\hline \multirow{2}{*}{$\begin{array}{l}\text { Fonte de } \\
\text { variação }\end{array}$} & \multirow[b]{2}{*}{ GL } & \multicolumn{3}{|c|}{ Quadrados médios (significância) } \\
\hline & & NB & $\mathrm{CMB}$ & $\begin{array}{c}\text { Formação } \\
\text { de calos }(\%)\end{array}$ \\
\hline Genótipo (G) & 5 & $8,830^{*}$ & $41,701 *$ & $4.177,96^{*}$ \\
\hline $\mathrm{GA}_{3}$ & 3 & $9,570 *$ & $88,700^{*}$ & $16.827,60^{*}$ \\
\hline$(\mathrm{G}) * \mathrm{GA}_{3}$ & 15 & $2,416^{*}$ & $3,750 *$ & $701,25^{\text {ns }}$ \\
\hline Resíduo & 96 & 0,9461 & 1,877 & 601,87 \\
\hline Média & - & 2,73 & 6,48 & 31,66 \\
\hline AS & & 0,94 & 0,97 & 0,92 \\
\hline
\end{tabular}

${ }^{\text {ns }} \mathrm{F}$ não-significativo a $5 \%$ de probabilidade; ${ }^{*} \mathrm{~F}$ significativo a $5 \%$ de probabilidade; $\mathrm{AS}=$ acurácia seletiva, faixas: $\leq 0,5$ (Baixa); 0,5<AS 0,7 (Moderada); 0,7< AS 0,9 (Alta); >0,9 (Muito Alta).

Para o número de brotações alongadas houve ajuste polinomial quadrático para todas as curvas, observandose interação entre genótipos e concentrações de $\mathrm{GA}_{3}$. Por conseguinte, o comportamento dos genótipos é diferente quando se varia a concentração de $\mathrm{GA}_{3}$ (Figura 1).

Para a maioria dos genótipos, a ausência de $\mathrm{GA}_{3}$ resultou no maior número de brotações alongadas por explante. Os genótipos 7, 2 e 10 apresentaram, inclusive, grande redução no número de brotações quando foi adicionada a giberelina, mesmo na menor concentração testada $\left(0,2 \mathrm{mg} \mathrm{L}^{-1}\right)$. Esses resultados sugerem um efeito inibitório do $\mathrm{GA}_{3}$ sobre alongamento caulinar em Eucalyptus dunnii. Já, o genótipo 6 apresentou redução, observada na maior concentração testada, porém essa diminuição foi de menor magnitude. Está registrado na literatura que o uso de $\mathrm{GA}_{3}$, em algumas situações, pode inibir a proliferação de partes aéreas (GRATTAPAGLIA; MACHADO, 1998).

Por outro lado, os genótipos 3 e 4 não apresentaram grande variação no número de brotações com a adição de $\mathrm{GA}_{3}$, sendo que o genótipo 4, inclusive, apresentou um

Cerne, Lavras, v. 19, n. 4, p. 545-550, out./dez. 2013 
Genótipo 3: $\mathrm{y}=3,90301-2,2965 \mathrm{x}+2,62272 \mathrm{x}^{2}-\mathrm{R}^{2}=0,92$ Genótipo 7: $\mathrm{y}=4,61225-9,67133 \mathrm{x}+9,6681 \mathrm{x}^{2}-\mathrm{R}^{2}=0,87$ Genótipo 6: $\mathrm{y}=2,9614+1,765409 \mathrm{x}-2,99204 \mathrm{x}^{2}-\mathrm{R}^{2}=0,97$ Genótipo 2: $y=3,8609-8,72036 \mathrm{x}+7,5818 \mathrm{x}^{2}-\mathrm{R}^{2}=0,86$ Genótipo 10: $\mathrm{y}=4,0416-11,9671+11,0159 \mathrm{x}^{2}-\mathrm{R}^{2}=0,99$

Genótipo 4: $\mathrm{y}=1,7095+0,96304 \mathrm{x}-0,460227 \mathrm{x}^{2}-\mathrm{R}^{2}=0,84$

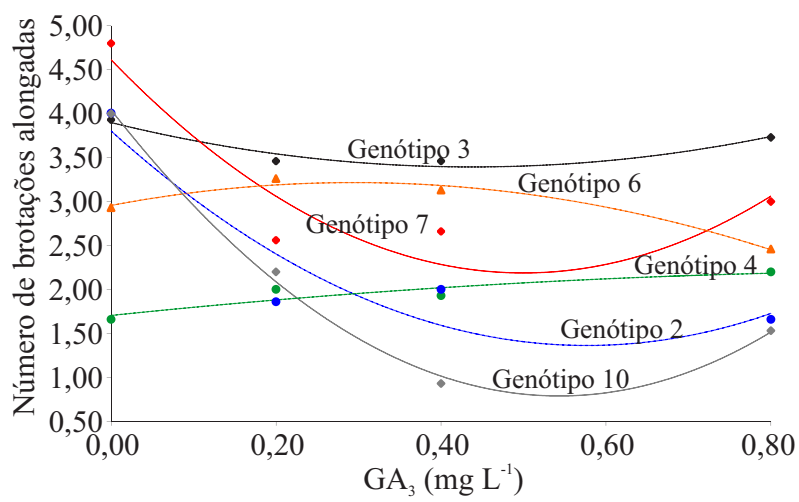

Figura 1 - Número de brotações alongadas por explante em genótipos de Eucalyptus dunnii, após 30 dias de cultivo in vitro em meio nutritivo $1 / 2 \mathrm{MS}$, em função das concentrações de GA. Santa Maria-RS/UFSM, 2010.

Figure 1-Number of elongated shoots per explant in genotypes of Eucalyptus dunnii, after 30 days of in vitro culture in nutritive medium $1 / 2 M S$, depending on the $G A_{3}$ concentrations. Santa Maria-RS/UFSM, 2010.

leve aumento nas brotações alongadas com o aumento da concentração da giberelina. O genótipo 3 apresentou o maior número de brotações alongadas na ausência de $\mathrm{GA}_{3}$ e, também, na maior concentração testada $(0,8$ $\mathrm{mg} \mathrm{L}^{-1}$ ), entretanto, na presença de $0,8 \mathrm{mg} \mathrm{L}^{-1}$ de $\mathrm{GA}_{3}$ houve formação de calos na base dos explantes, o que é indesejável na multiplicação. Pode-se observar, portanto, uma recalcitrância dos genótipos 2 e 10 para o alongamento na presença de $\mathrm{GA}_{3}$ e, para o genótipo 4, independente da giberelina.

Os resultados obtidos no presente estudo foram discordantes daqueles observados em clones de Eucalyptus benthamii x Eucalyptus dunnii em que o maior alongamento das brotações ocorreu na presença de 0,1 ou $0,2 \mathrm{mg} \mathrm{L}^{-1} \mathrm{de}$ $\mathrm{GA}_{3}$ combinados com $0,1 \mathrm{mg} \mathrm{L}^{-1}$ de BAP e $0,5 \mathrm{mg} \mathrm{L}^{-1}$ de ANA (BRONDANI, 2008).

Para o comprimento das brotações alongadas houve, igualmente, um ajuste polinomial quadrático para todos os genótipos, observando-se interação entre os fatores principais (Figura 2).

Quanto ao comprimento das brotações alongadas, obteve-se comportamento semelhante ao número de
Genótipo 3: $\mathrm{y}=311,5803-19,9368 \mathrm{x}+18,3793 \mathrm{x}^{2}-\mathrm{R}^{2}=0,84$

Genótipo 2: $y=10,7848-19,9160 x+17,1704 x^{2}-R^{2}=0,90$

Genótipo 4: $\mathrm{y}=10,042-22,2143 \mathrm{x}-22,21136 \mathrm{x}^{2}-\mathrm{R}^{2}=0,90$

Genótipo 7: $y=7,5326-7,62063 x+5,04321 x^{2}-R^{2}=0,86$

Genótipo 6: $y=6,8631-7,91868 \mathrm{x}+8,3784 \mathrm{x}^{2}-\mathrm{R}^{2}=0,89$

Genótipo 10: $\mathrm{y}=5,9258-10,78668+10,2784 \mathrm{x}^{2}-\mathrm{R}^{2}=0,99$

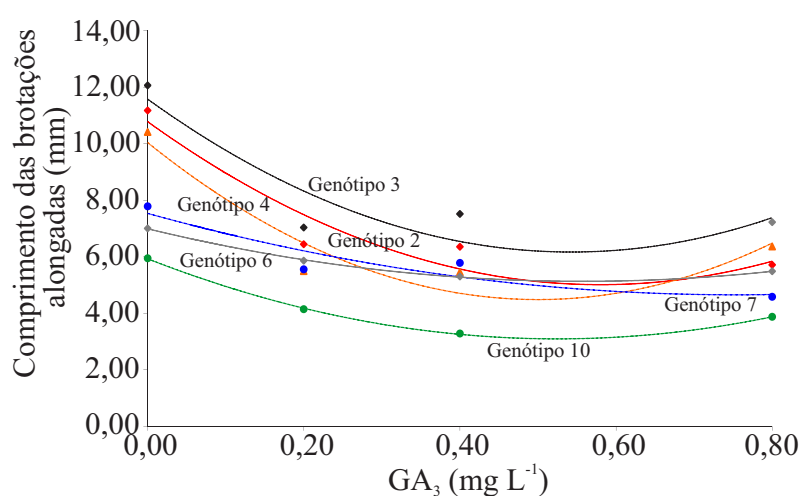

Figura 2 - Comprimento médio das brotações alongadas (mm) em genótipos de Eucalyptus dunnii, após 30 dias de cultivo in vitro em meio nutritivo $1 / 2 \mathrm{MS}$, em função das concentrações de $\mathrm{GA}_{3}$. Santa Maria-RS/UFSM, 2010.

Figure 2-Average length of elongated shoots ( $\mathrm{mm}$ ) of genotypes of Eucalyptus dunnii, 30 days after inoculation, depending on the $\mathrm{GA}_{3}$ treatments. Santa Maria-RS/UFSM, 2010.

brotações alongadas, em que, na ausência de $\mathrm{GA}_{3}$ observaram-se os melhores resultados. Em geral, os genótipos que apresentaram maior número de brotações também foram aqueles cujas brotações tiveram maior tamanho. O genótipo 4 constituiu-se em uma exceção, obtendo a menor média de brotações alongadas e, simultaneamente, um dos maiores comprimentos médios de brotações entre os seis genótipos avaliados, principalmente na ausência de $\mathrm{GA}_{3}$.

Todos os genótipos apresentaram brotações mais compridas na ausência de $\mathrm{GA}_{3}$, havendo grande diminuição no comprimento das brotações com a adição dessa giberelina o que indica que a combinação ANA e BAP é suficiente para promover o alongamento in vitro de segmentos nodais de Eucalyptus dunnii.

Em brotações de árvores de 30 anos de idade de Eucalyptus tereticornis $\mathrm{x}$ Eucalyptus grandis multiplicadas em meio nutritivo MS adicionado de $1 \mathrm{mg} \mathrm{L}^{-1} \mathrm{de}$ BAP combinado com $1 \mathrm{mg} \mathrm{L}^{-1}$ de ANA foi obtido um comprimento médio de 25 a $30 \mathrm{~mm}, 15$ dias após a inoculação dos explantes (JOSHI et al., 2003). Em Eucalyptus urophylla o comprimento médio das brotações alongadas foi de $25 \mathrm{~mm}$ após 40 dias de cultivo in vitro,

Cerne, Lavras, v. 19, n. 4, p. 545-550, out./dez. 2013 
utilizando $0,1 \mathrm{mg} \mathrm{L}^{-1}$ de Benziladenina (BA), 0,1 $\mathrm{mg} \mathrm{L}^{-1}$ de ANA e 0,1 mg L-1 de GA $\mathrm{mg}_{3}$ (HUNG et al., 2010). Provavelmente, as diferentes espécies e idades das árvores tenham interferido na resposta observada, com o maior alongamento ocorrendo na presença da giberelina.

Quanto à formação de calos, os genótipos 7, 2, 3 e 10 apresentaram as menores médias, diferenciando-se de 6 e 4 (Tabela 2). O genótipo 4 foi o que apresentou a maior média de formação calogênica.

Tabela 2 - Formação de calos (\%) em genótipos de Eucalyptus dunnii aos 30 dias de cultivo in vitro em meio nutritivo $1 / 2 \mathrm{MS}$. Santa Maria-RS/UFSM, 2010.

Table 2 - Calli formation (\%) in genotypes of Eucalyptus dunnii at 30 days of in vitro culture on $1 / 2$ MS nutritive medium. Santa Maria-RS/UFSM, 2010.

\begin{tabular}{cc}
\hline Genótipo & Formação de calos $(\%)$ \\
\hline 7 & $15,0 \mathrm{a}^{*}$ \\
2 & $23,33 \mathrm{a}$ \\
3 & $26,6 \mathrm{a}$ \\
10 & $30,0 \mathrm{a}$ \\
6 & $38,3 \mathrm{~b}$ \\
4 & $56,66 \mathrm{c}$ \\
\hline
\end{tabular}

*Médias seguidas pela mesma letra na coluna, não diferem entre si pelo teste de Scott-Knott a 5\% de probabilidade de erro.

A elevada formação de calos no genótipo 4 pode, portanto, explicar o reduzido número de brotações alongadas. A formação dessas estruturas prejudica o cultivo in vitro, quando o objetivo é a propagação direta. A formação de calos na base do explante pode comprometer a proliferação de gemas axilares e o alongamento de brotações, afetando o desenvolvimento in vitro (GRATTAPAGLIA; MACHADO, 1998).

Em relação à concentração de $\mathrm{GA}_{3}$ no meio nutritivo, a formação de calos ajustou-se a uma função quadrática positiva (Figura 3), com o aumento da concentração da giberelina observou-se cerca de 55\% de explantes com estruturas calogênicas a $0,8 \mathrm{mg} \mathrm{L}^{-1}$. Apenas na ausência de $\mathrm{GA}_{3}$ no meio nutritivo testado para o alongamento in vitro não foram formados calos nas brotações.

De uma maneira geral, a adição de $\mathrm{GA}_{3}$ no meio nutritivo não foi favorável ao alongamento. Ao contrário, a presença da giberelina promoveu um reduzido alongamento, menor tamanho das brotações e formação de estruturas calogênicas.

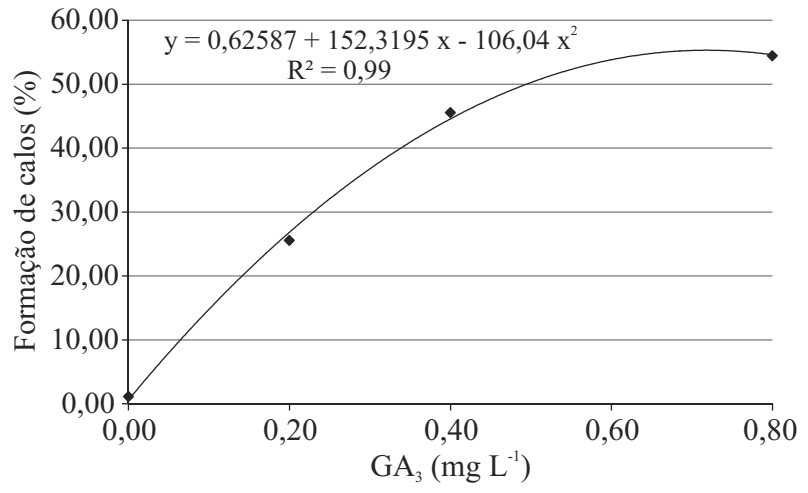

Figura 3 - Brotações de Eucalyptus dunnii apresentando formação de calos (\%) após 30 dias de cultivo in vitro em meio nutritivo $1 / 2 \mathrm{MS}$ acrescido de diferentes concentrações de $\mathrm{GA}_{3}$. Santa Maria-RS/UFSM, 2010.

Figure 3 - Shoots of Eucalyptus dunnii showing calli formation (\%) after 30 days of in vitro culture on $1 / 2$ MS nutritive medium supplemented with different concentrations of $\mathrm{GA}_{3}$. Santa MariaRS/UFSM, 2010.

\section{CONCLUSÕES}

Ácido giberélico $\left(\mathrm{GA}_{3}\right)$ não apresenta efeito no alongamento in vitro de Eucalyptus dunnii. Na presença de $\mathrm{GA}_{3}$ os genótipos reduzem o número de brotações alongadas e o comprimento das brotações, aumentando a formação de calos. Os genótipos testados apresentam desempenho in vitro diferenciado em relação ao alongamento, o qual é passível de seleção.

\section{AGRADECIMENTOS}

Os autores agradecem à empresa Stora Enso pelo fornecimento do material vegetal para coleta.

\section{REFERÊNCIAS}

ALFENAS, A. C.; ZAUZA, E. A. V.; MAFIA, R. G.; ASSIS, T. F. Clonagem e doenças do eucalipto. Viçosa, MG: UFV, 2004. 442 p.

BILLARD, C. E.; LALLANA, V. H. Multiplicación in vitro de Eucalyptus dunnii. Ciencia, Docência y Tecnologia, Córdoba, ano 16, n. 30, p. 200-206, 2005.

BRONDANI, G. E. Miniestaquia e micropropagação de Eucalyptus benthamii Maiden \& Cambage X Eucalyptus dunnii Maiden. 2008. 129 p. Dissertação (Mestrado Engenharia Florestal) - Universidade Federal do Paraná, Curitiba, 2008.

Cerne, Lavras, v. 19, n. 4, p. 545-550, out./dez. 2013 
CALDERON-BALTIERRA, X. V. Influencia del cálcio y ácido giberélico em el alargamiento de brotes adventícios in vitro de Eucalyptus glubulus. Bosque, Valdívia, v. 15, n. 1, p. 33-38, 1994.

CORREIA, D.; GONÇALVES, A. N.; COUTO, H. T. Z.; RIBEIRO, M. C. Efeito do meio de cultura líquido e sólido no crescimento e desenvolvimento de gemas de E. grandis $\mathrm{x}$ E. urophylla na multiplicação in vitro. IPEF, Piracicaba, v. 48/49, p. 107-116, 1995.

FERREIRA, D. F. Análises estatísticas por meio do Sisvar para Windows versão 4.0. In: REUNIÃO ANUAL DA REGIÃO BRASILEIRA DA SOCIEDADE INTERNACIONAL DE BIOMETRIA, 45., 2000, São Carlos. Anais... São Carlos: UFSCar, 2000. p. 255-258.

GRATTAPAGLIA, D.; ASSIS, T. F.; CALDAS, L. S. Efeito residual de BAP e NAA na multiplicação e enraizamento in vitro de Eucalyptus. In: SIMPÓSIO NACIONAL DE CULTURA DE TECIDOS VEGETAIS, 2., 1987, Brasília. Anais... Brasília: EMBRAPA, 1987. p. 8.

GRATTAPAGLIA, D.; MACHADO, M. A. Micropropagação. In: TORRES, A. C.; CALDAS, L. S.; BUSO, J. A. (Ed.). Cultura de tecidos e transformação genética de plantas. Brasília: EMBRAPA-SPI; EMBRAPA-CNPH, 1998. p. 183260.

HU, C. Y.; WANG, P. J. Meristem, shoot tip and bud cultures. In: EVANS, D. A.; SHARP, W. R.; AMMIRATO, P. V.;
YAMADA, Y. (Ed.). Handbook of plant cell culture. New York: MacMillan, 1983. v. 1, p. 177-227.

HUANG, Z. C.; ZENG, F. H.; LU, X. Y. Efficient regeneration of Eucalyptus urophylla from seedling-derived hypocotyls. Biologia Plantarum, Copenhagen, v. 54, n. 1, p. 131-134, 2010.

JOSHI, I. et al. In vitro clonal propagation of mature Eucalyptus $\mathrm{F}_{1}$ hybrid (E. tereticornis Sm. X E. grandis Hill ex Maiden). Silvae Genetica, Frankfurt, v. 52, n. 3/4, p. 110-113, 2003.

MÉTRAUX, J. P. Gibberellins and plant cell elongation. In: DAVIES, P. J. (Ed.). Plant hormones and their role in plant growth and development. Dordrecht: M. Nijhoff, 1987. p. 296-317.

MURASHIGE, T.; SKOOG, F. A revised medium for rapid growth and bioassays with tobacco tissue cultures. Physiologia Plantarum, Copenhagen, v. 15, p. 473-497, 1962.

RESENDE, M. D. V. de; DUARTE, J. B. Precisão e controle de qualidade em experimentos de avaliação de cultivares. Pesquisa Agropecuária Tropical, Goiânia, v. 37, p. 182-194, 2007.

SILVA, E. S. B. Propagação in vitro de Prunus spp. 2004. 115 f. Tese (Doutorado em Fruticultura de Clima Temperado) Universidade Federal de Pelotas, Pelotas, 2004.

XAVIER, A.; WENDLING, I.; SILVA, R. L. Silvicultura clonal: princípios e técnicas. Viçosa, MG: UFV, 2009. 272 p.

Recebido: 1 de junho de 2011; aceito: 24 de maio de 2013.

Cerne, Lavras, v. 19, n. 4, p. 545-550, out./dez. 2013 